\title{
Materials Selection and Design of Microelectrothermal Bimaterial Actuators
}

\author{
Srinivasan Prasanna and S. Mark Spearing, Member, ASME
}

\begin{abstract}
A common form of MEMS actuator is a thermally actuated bimaterial, which is easy to fabricate by surface micromachining and permits out of plane actuation, which is otherwise difficult to achieve. This paper presents an analytical framework for the design of such microelectrothermal bimaterial actuators. Mechanics relationships for a cantilever bimaterial strip subjected to a uniform temperature were applied to obtain expressions for performance metrics for the actuator, i.e., maximum work/volume, blocked (force) moment, and free-end (displacement) slope. Results from finite-element analysis and closed form relations agree well to within $1 \%$. The optimal performance for a given pair of materials and the corresponding thickness ratio were determined. Contours of equal performance corresponding to commonly used substrates (e.g., $\mathrm{Si}, \mathrm{SiO}_{2}$ ) were plotted in the domain of governing material properties (thermal expansion coefficient and Young's modulus) to identify candidate materials for further development. These results and the accompanying methodology provide a rational basis for comparing the suitability of "standard" materials for microelectrothermal actuators, as well as identifying materials that might be suitable for further research.

[2006-0086]
\end{abstract}

Index Terms-Microactuators, optimization, performance and thermoelasticity.

\section{INTRODUCTION}

$\mathbf{T}$ HE performance of microsystems is strongly governed by the interaction between the material and the microfabrication process used. The evolution of microelectromechanical systems (MEMS) from complementary metal oxide semiconductor (CMOS)/ metal-oxide-semiconductor field-effect transistor (MOSFET) technology has paved the way for designers to consider a limited set of conventionally used semiconductor materials for microsystem design. These materials are not necessarily optimal, particularly for micromechanical transducers [1]. As MEMS diverges from the conventional CMOS technology, there is an opportunity to expand the range of available materials and associated fabrication routes, particularly for MEMS actuators. A recent study on classifying MEMS actuators into families based on their actuation principle and their performance provides a basis by which to identify areas of overall improvement in actuator design [2]. Electrothermal actuators in

Manuscript received May 9, 2006; revised September 11, 2006. This work was supported by the Overseas Research Students Awards Scheme. The work of S. Prasanna was supported by the University of Southampton, Southampton, U.K.. The work of S. M. Spearing was supported by a Royal Society Wolfson Research Merit Award. Subject Editor C. Liu.

The authors are with the School of Engineering Sciences, University of Southampton, Southampton, SO171BJ, U.K. (e-mail: prasanna@soton.ac.uk; prasri@gmail.com; spearing@soton.ac.uk).

Color versions of one or more of the figures in this paper are available online at http://ieeexplore.ieee.org.

Digital Object Identifier 10.1109/JMEMS.2006.889528 general, are particularly promising for delivering large displacements $(1-100 \mu \mathrm{m})$ and/or high forces $(10-100 \mu \mathrm{N})$. Thermal bimaterial actuators, made by simple MEMS fabrication processes provide an easy means to obtain out-of-plane actuation which is otherwise difficult to achieve. Their actuation typically utilizes the resistance heating of the actuator elements resulting in differential thermal expansion.

Several bimaterial electrothermal actuators have been demonstrated: a diamond-like carbon (DLC)/Ni microcage [3], a polymeric microgripper made of SU8 integrated with Ti/Pt [4] and gold-polyimide on silicon wafers [5] have been suggested as biocompatible actuators for handling living cells in certain biomedical and biological applications. Submicron scale electrothermal actuators [6] have been proposed as precise end-effectors for robots. Aluminium films on single crystal silicon [7] have been developed for optical applications such as positioning micromirrors. Thermally actuated probe arrays made of gold on silicon nitride were used for nanolithography [8] applications. A ternary alloy $\mathrm{Al}_{\mathrm{x}} \mathrm{Ga}_{1-\mathrm{x}} \mathrm{As}$ deposited on GaAs substrate [9], and SU8 polymer coated on silicon [10] were considered for micromachined cantilevers for use in atomic force microscopy. In all these applications, it is clear that the choice of materials has been largely driven by what is available to the designers rather than what should be considered for an optimal performance.

Although different approaches to electrothermal actuation [11]-[14] provide flexibility in meeting functional requirements, surprisingly little attention has focussed on optimizing microsystem design based on materials selection. The few published works in this area include: a comparison of the performance of Ti-Al films and Al films on silicon [15] emphasizing the potential of Ti-Al films in bimaterial actuator design, application of Ashby's approach for selecting suitable candidate materials for purely mechanical elements of the actuator [16] and comparison of the performance of bimaterials and their reliability in macro system applications via performance maps [17].

The present paper discusses a strategy for selecting candidate materials for thermally actuated bimaterial actuators, in order to obtain maximum performance. The performance metrics considered are blocked moment, free-end slope, and the maximum work per volume. Blocked moment and free-end slope correspond to the maximum force and maximum displacement achievable. Material combinations that can deliver a large tip slope/displacement, when thermally actuated under fixed-free condition are suitable candidates for applications such as micromirrors. Blocked force is an important performance criterion for applications such as valves in microfluidic devices. Maximum work/volume is a relevant metric in the 


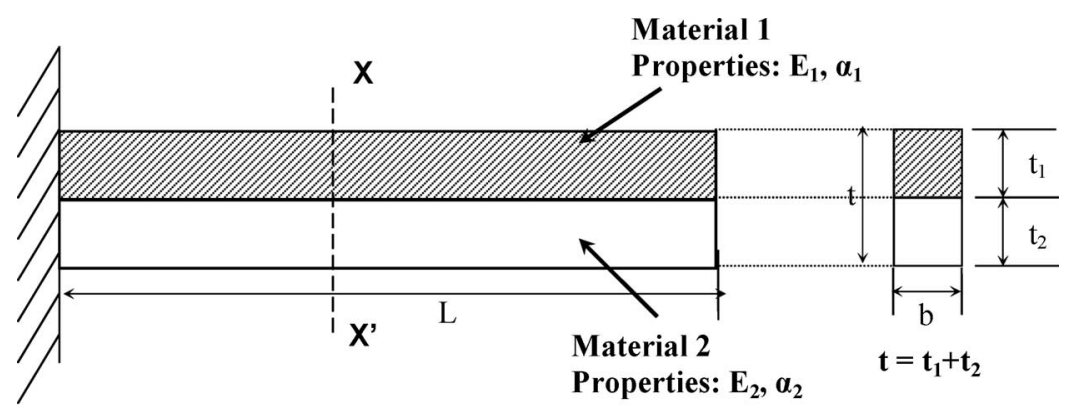

(a)

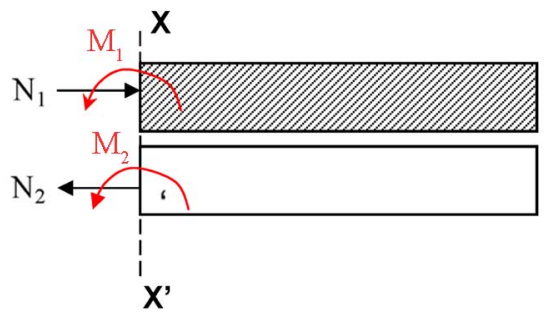

(b)

Fig. 1. (a) Geometric definition of a bimaterial cantilever. (b) Mechanics of a bimaterial cantilever subjected to a uniform temperature difference $\Delta \mathrm{T}$.

design of actuators for displacement micropumps or other flow control devices. The primary objective of the present study is to develop an approach for identifying candidate materials in the preliminary design phase of microelectrothermal actuators which can deliver high steady state thermomechanical response. Hence, variation in temperature field due to electric effects, heat dissipation due to different modes of heat transfer and estimation of maximum permissible actuation temperature are not addressed at this stage but these topics are the focus of ongoing research. The effect of scale and processing route on material properties at the microscale are also not considered. These factors clearly require consideration in the detailed design of a bimaterial actuator.

This paper is organized as follows. Section II discusses the mechanics of a thermal bimaterial actuator. Closed form solutions for performance metrics and comparison with results of finite-element analysis are illustrated in Section III. The mathematical formulations associated with the optimization of the performance metrics are discussed in Section IV. Section V presents the materials selection strategy based on the optimization of performance metrics. Section VI discusses the process employed for candidate materials selection and other factors to be accounted for during the materials selection. Finally, Section VII contains concluding remarks of this study.

\section{Mechanics of A Thermal Bimaterial ACtUAtor}

Fig. 1(a) shows a cantilever thermal bimaterial actuator made of two dissimilar materials with Youngs moduli $\mathrm{E}_{1}, \mathrm{E}_{2}$ and thermal expansion coefficients $\alpha_{1}, \alpha_{2} . \mathrm{t}_{1}$ and $\mathrm{t}_{2}$ are the thickness of the layers and $\mathrm{L}$ is the beam length. In the analysis that follows, forces and moments are normalized by the width $b$. Fig. 1(b) shows the effective internal forces $\left(\mathrm{N}_{1}, \mathrm{~N}_{2}\right)$ and moments $\left(\mathrm{M}_{1}, \mathrm{M}_{2}\right)$ developed in each layer when the bimaterial is subjected to a uniform temperature difference $\Delta \mathrm{T}$. Timoshenko [18] was first to develop the fundamental mechanics of a bima-

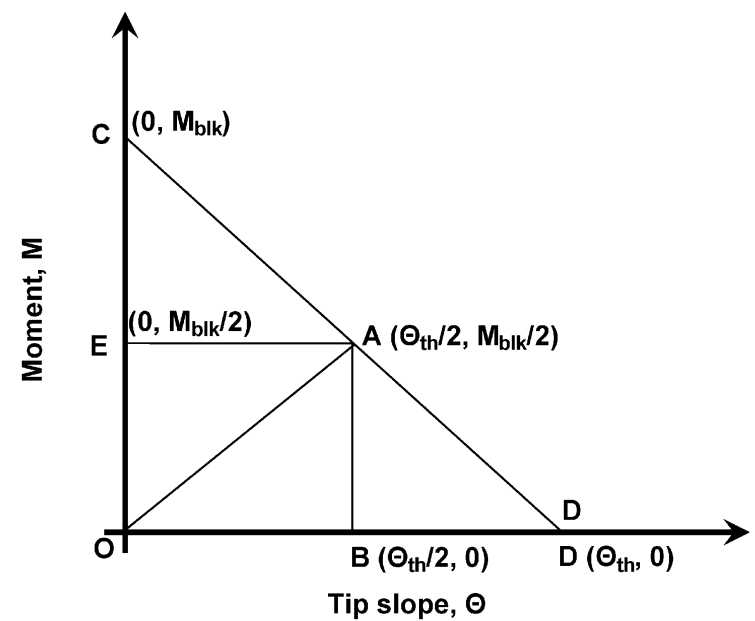

Fig. 2. Operating characteristics of a linear bimaterial electrothermal actuator.

terial (or bimetallic strip) subjected to a uniform temperature difference $\Delta \mathrm{T}$. Making the usual assumptions of simple beam theory and applying compatibility, equilibrium and constitutive relations to the system of forces and moments gives

$$
\begin{aligned}
\mathrm{N}_{1} & =\mathrm{N}_{2}=\frac{\mathrm{E}_{1} \mathrm{t}_{1}(\Delta \alpha)(\Delta \mathrm{T})\left(1+\lambda \xi^{3}\right)}{3 \lambda \xi(\xi+1)^{2}+(1+\lambda \xi)\left(1+\lambda \xi^{3}\right)} \\
\mathrm{M}_{1} & =\frac{\mathrm{E}_{1} \mathrm{t}_{1}^{2}(\Delta \alpha)(\Delta \mathrm{T})}{2\left(\frac{3 \lambda \xi(\xi+1)^{2}+(1+\lambda \xi)\left(1+\lambda \xi^{3}\right)}{\lambda \xi^{2}(\xi+1)}\right)} \\
\mathrm{M}_{2} & =\frac{\mathrm{E}_{1} \mathrm{t}_{1}^{2}(\Delta \alpha)(\Delta T)}{2 \xi\left(\frac{3 \lambda \xi(\xi+1)^{2}+(1+\lambda \xi)\left(1+\lambda \xi^{3}\right)}{(\xi+1)}\right)} .
\end{aligned}
$$

Where $\lambda=\mathrm{E}_{1} / \mathrm{E}_{2}$ is the elastic modulus ratio, $\xi=\mathrm{t}_{1} / \mathrm{t}_{2}$ is the thickness ratio and $\Delta \alpha=\left(\alpha_{1}-\alpha_{2}\right)$ is the difference in thermal expansion coefficient of the materials. 


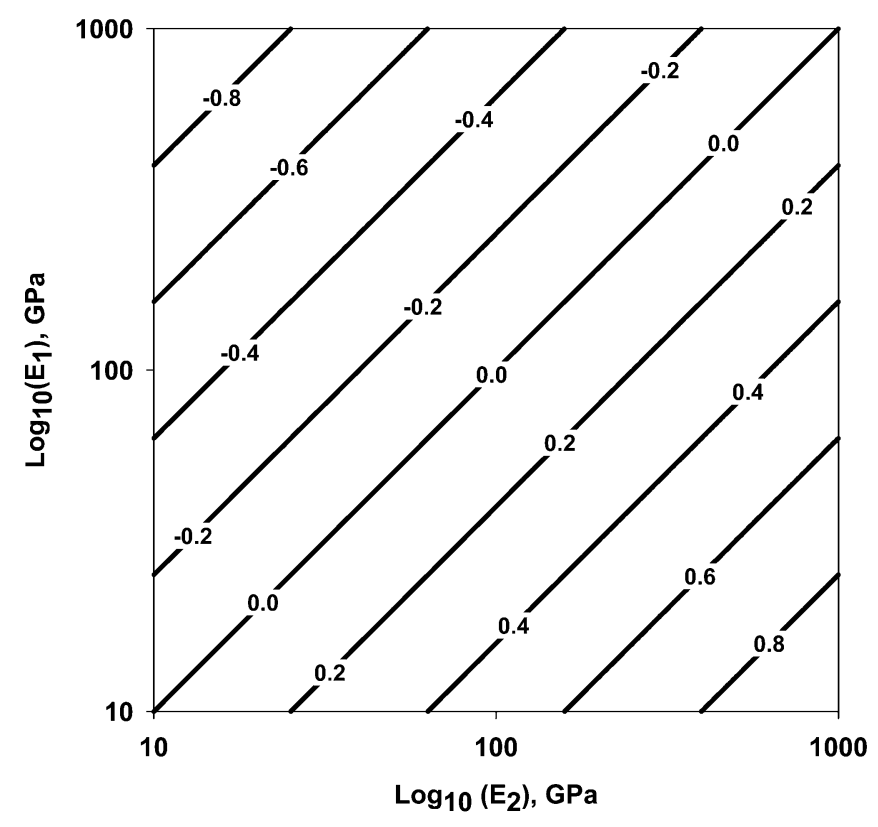

Fig. 3. Contours of optimal thickness ratio $\log _{10}\left(\xi_{\text {opt }}\right)$ for a given material pair to deliver maximum free-end slope, blocked moment, and work/volume.

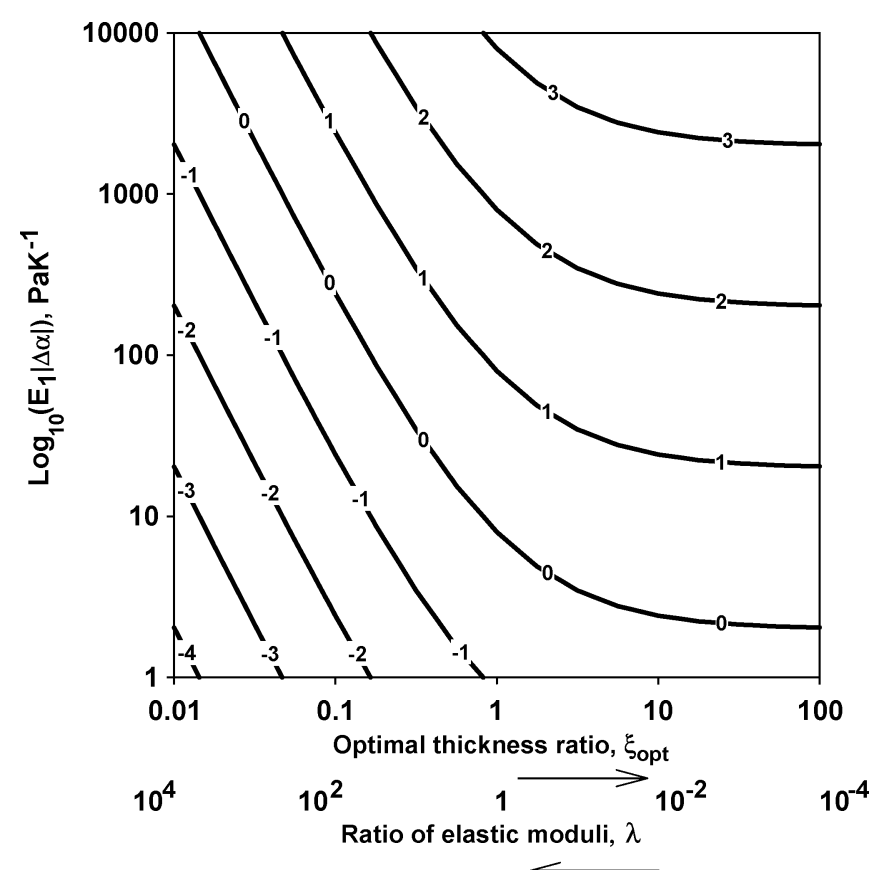

Fig. 4. Contours of optimal normalized moment $\log _{10}\left(M_{n}\right)_{\text {opt }}$ for a given pair of materials.

\section{Evaluation of The PERFORMANCE Metrics}

\section{A. Evaluation of Free-End Slope $\left(\Theta_{t h}\right)$}

The free-end slope developed when a bimaterial cantilever is subjected to a uniform temperature difference, $\Delta \mathrm{T}$ relative to the ambient temperature, is given by

$$
\Theta_{\mathrm{th}}=\frac{12 \mathrm{M}_{1} \mathrm{~L}}{\mathrm{E}_{1} \mathrm{t}_{1}^{3}} .
$$

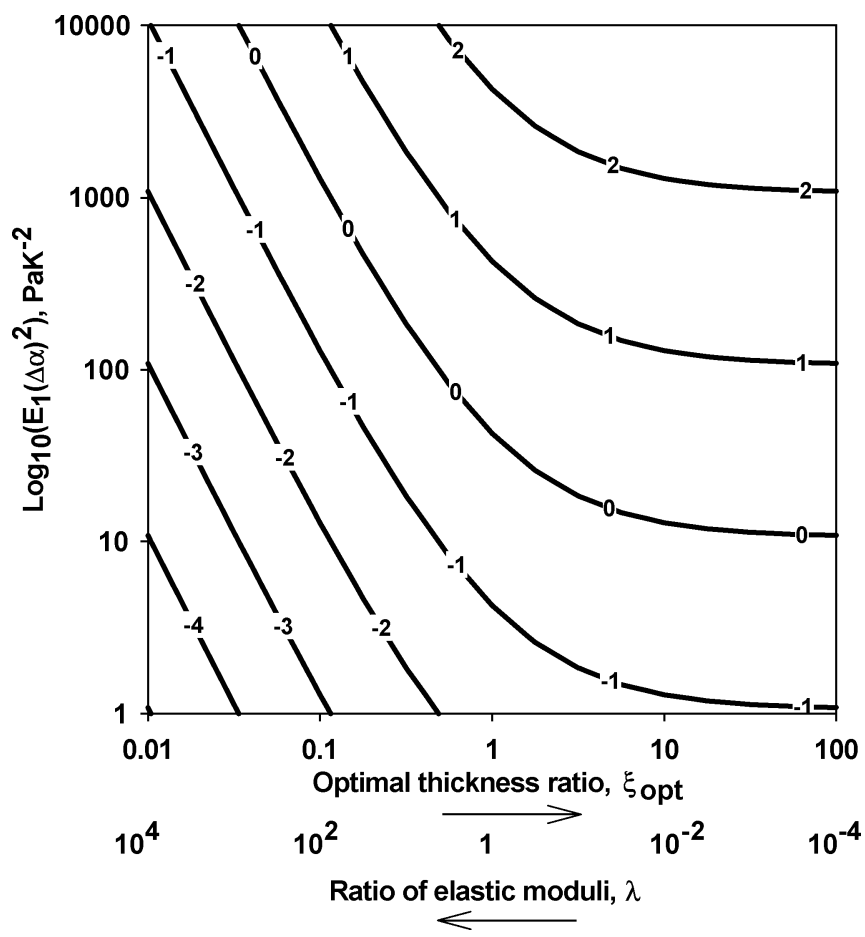

Fig. 5. Contours of optimal normalized work per volume $\log _{10}\left(W_{n}\right)_{\text {opt }}$ for a given pair of materials.

TABLE I

Material PROPERTIES OF CONVENTIONAL MATERIALS EMPLOYED IN MEMS DESIGN

\begin{tabular}{|l|c|c|}
\hline \multicolumn{1}{|c|}{ Materials } & $\begin{array}{c}\text { Youngs } \\
\text { Modulus, } \mathrm{E} \\
{[\mathrm{GPa}]}\end{array}$ & $\begin{array}{c}\text { Thermal expansion } \\
\text { co-efficient, } \alpha \\
{\left[\mu \mathrm{m} / \mathrm{m}^{\circ} \mathrm{K}\right]}\end{array}$ \\
\hline $\mathrm{SiO}_{2}$ & 75 & 0.4 \\
\hline $\mathrm{Si}_{3} \mathrm{~N}_{4}$ & 260 & 2.8 \\
\hline Diamond like Carbon (DLC) & 700 & 1.18 \\
\hline $\mathrm{SiC}$ & 460 & 4.51 \\
\hline $\mathrm{Si}$ & 165 & 2.49 \\
\hline $\mathrm{Ni}$ & 207 & 13.1 \\
\hline $\mathrm{Cu}$ & 110 & 16.4 \\
\hline $\mathrm{Al}$ & 68 & 24 \\
\hline $\mathrm{Au}$ & 77 & 14.4 \\
\hline Polyimide (a typical polymer) & 4 & 20 \\
\hline
\end{tabular}

Substituting (2) in (4) gives an expression for the free-end slope $\Theta_{\text {th }}$ as

$$
\Theta_{\mathrm{th}}=\frac{6(\Delta \alpha)(\Delta \mathrm{T}) \mathrm{L}}{\mathrm{t}_{1}\left(\frac{(1+\lambda \xi)\left(1+\xi^{3} \lambda\right)+3 \lambda \xi(\xi+1)^{2}}{\lambda \xi^{2}(\xi+1)}\right)} .
$$

\section{B. Evaluation of Blocked Moment $\left(M_{b l k}\right)$}

When the free end of a bimaterial cantilever is rigidly fixed, a moment ( $\mathrm{M}_{\mathrm{blk}}$, the blocked moment) is developed on heating it to a uniform temperature. This blocked moment can be evaluated by applying the principle of superposition between the free-end slope given by (5) and an equivalent free-end slope due 


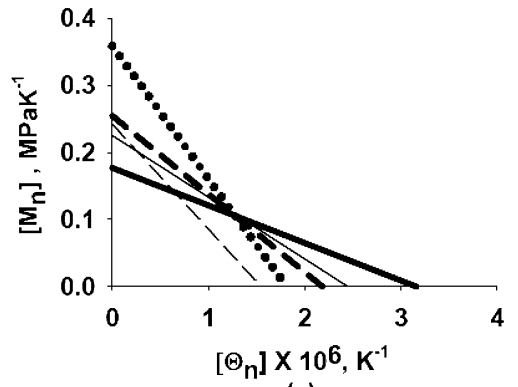

(a)

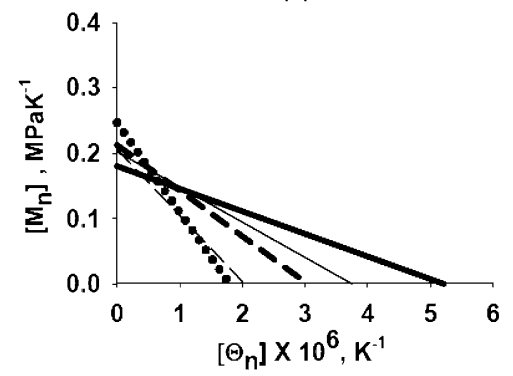

(c)

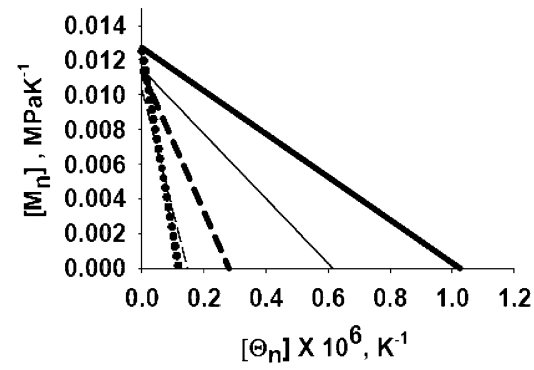

(e)

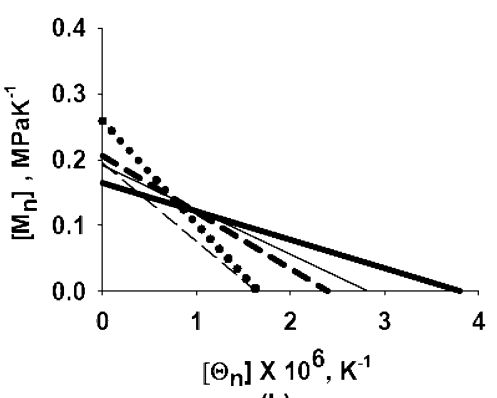

(b)

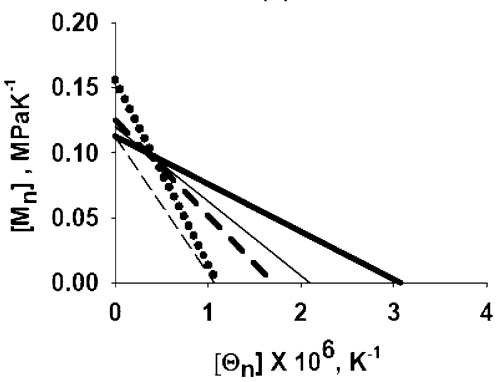

(d)

Fig. 6. Comparison of the operating characteristics of a bimaterial actuator made of different substrates with: (a) nickel; (b) copper; (c) aluminium; (d) gold; and (e) polyimide for $\xi=0.5$.

to an arbitrary mechanical moment, $\mathrm{M}_{\mathrm{blk}}$ obtained using composite beam theory [19]. The blocked moment $\mathrm{M}_{\mathrm{blk}}$ is evaluated as

$$
\mathrm{M}_{\mathrm{blk}}=\frac{\mathrm{E}_{1} \mathrm{t}_{1}^{2}(\Delta \alpha)(\Delta \mathrm{T})}{\left(\frac{2 \xi(1+\lambda \xi)}{(\xi+1)}\right)}
$$

\section{Evaluation of Maximum Work per Volume (W)}

In general, actuators are required to deliver finite displacements while applying finite loads. Therefore the most general performance metric for a compact actuator is the maximum work (energy) that can be delivered per unit volume.

Fig. 2 shows graphically the operating characteristics of a linear bimaterial actuator. Point $\mathrm{C}$ on the ordinate $\mathrm{M}$ corresponds to the fixed-fixed condition and point $\mathrm{D}$ on the abscissa, $\Theta$ corresponds to the fixed-free condition. Any point on the line CD corresponds to a compliant condition with moments and slopes bounded by those at $\mathrm{C}$ and $\mathrm{D}$. The maximum work per volume $(\mathrm{W})$ is equal to the triangular area $\mathrm{OAB}$ and it is given by

$$
\mathrm{W}=\frac{\mathrm{M}_{\mathrm{blk}} \Theta_{\mathrm{th}}}{8 \mathrm{Lt}}
$$

Substituting (5) and (6) in (7) gives an expression for the maximum work per volume

$$
\mathrm{W}=\frac{3 \mathrm{E}_{1}(\Delta \alpha)^{2}(\Delta \mathrm{T})^{2}}{8\left(3(\lambda \xi+1)+\left(\frac{(1+\lambda \xi)^{2}\left(1+\xi^{3} \lambda\right)}{\lambda \xi(\xi+1)^{2}}\right)\right)\left(\frac{\xi+1}{\xi}\right)}
$$

The closed-form relations for performance metrics given by (5), (6), and (8) were compared to the results obtained by finite-element analysis. A SOLID45 finite-element routine implemented in ANSYS 6.0 was used to analyze cantilever structures with an aspect ratio (L/t) of 10 for $0.01<\xi<100$, $0.01<\lambda<100$, with a temperature difference $\Delta \mathrm{T}=10^{\circ} \mathrm{C}$. In all cases, the numerical solutions obtained from finite-element analysis agreed with these analytical solutions to within $1 \%$.

\section{OPTIMIZATION OF PERFORMANCE METRICS}

\section{A. Optimization of Free-End Slope/Displacement $\left(\Theta_{\mathrm{th}}\right)$}

From (5), it is evident that the free-end slope of a thermal bimaterial actuator solely depends on the materials used (quantified by $\mathrm{E}$ and $\alpha$ ) and the thickness ratio for a given temperature change, $\Delta \mathrm{T}$. This observation simplifies the task of optimizing the design in order to maximize $\Theta_{\mathrm{th}}$. Since the material domain 


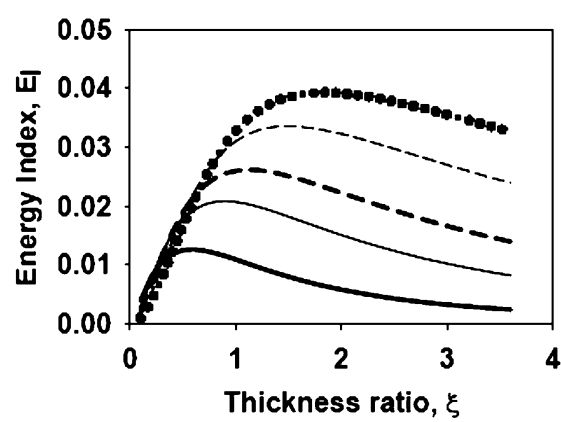

(a)

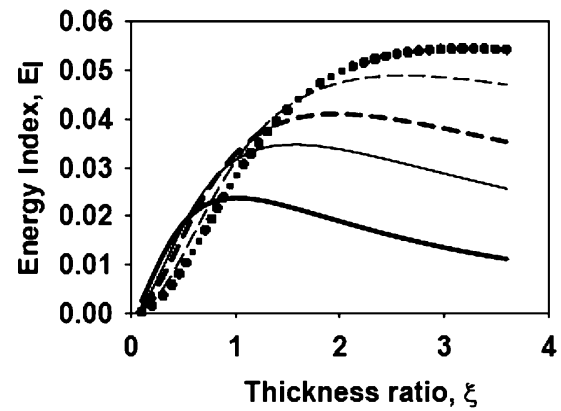

(c)

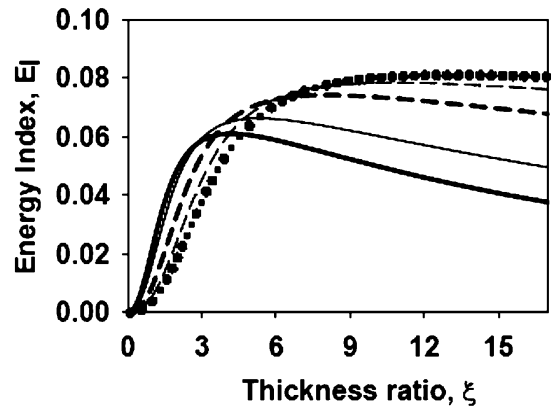

(e)

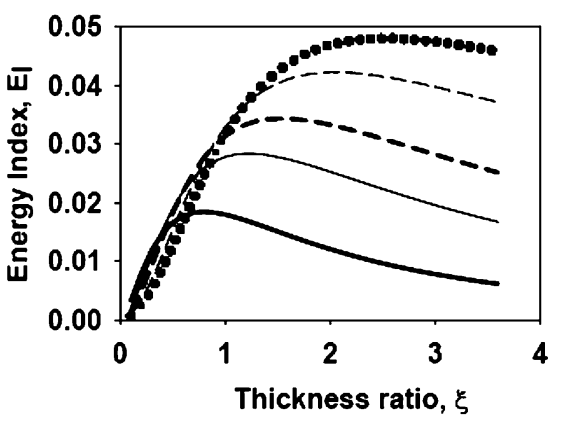

(b)

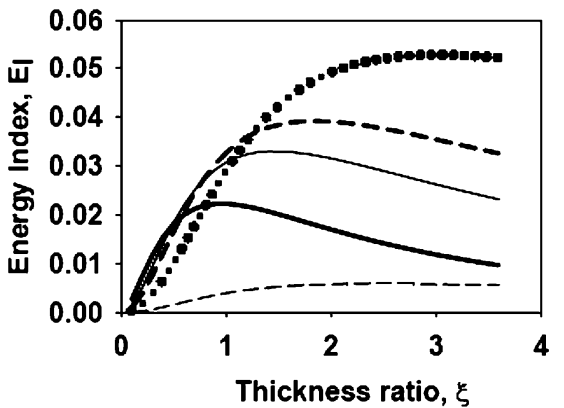

(d)

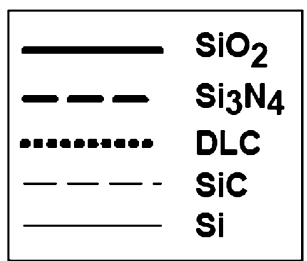

Fig. 7. Comparison of the energy indices of (a) nickel (b) copper (c) aluminium (d) gold and (e) polyimide on different substrates

is discrete in nature, i.e., a given material has particular values of $\mathrm{E}$ and $\alpha$ which are independent, it is most productive to optimize $\Theta_{\text {th }}$ with respect to the thickness ratio, $\xi$ for a given pair of materials. This implies that for a given $\Delta \alpha$ and a fixed aspect ratio under a constant temperature difference, $\Delta \mathrm{T}$ the denominator in (5) should be minimized in order to obtain a maximum performance. A normalized slope $\left(\Theta_{n}\right)$ is defined using the expression for the free-end slope given by (5).

$$
\Theta_{\mathrm{n}}=\frac{\Theta_{\mathrm{th}}}{6(\Delta \mathrm{T}) \beta}=\frac{(\Delta \alpha)}{\left(3+\mathrm{Z}_{\theta}\right)}
$$

where $\beta=\mathrm{L} / \mathrm{t}$ is the aspect ratio of the bimaterial cantilever and

$$
\mathrm{Z}_{\theta}=\frac{(1+\lambda \xi)\left(1+\xi^{3} \lambda\right)}{\lambda \xi(\xi+1)^{2}} .
$$

To maximize $\Theta_{\mathrm{n}}\left(\Theta_{\mathrm{th}}\right)$ for a given $\Delta \alpha, \mathrm{Z}_{\theta}$ should be minimized subject to

$$
\lambda>0 \text { is constant and } \xi>0 .
$$

The optimal thickness ratio that provides maximum $\Theta_{\mathrm{n}}$ is given by

$$
\frac{\partial \mathrm{Z}_{\theta}}{\partial \xi}=0 \text { for a constant } \lambda \text {. }
$$

Substituting (10) in (12) gives one admissible solution for the optimal thickness ratio $\left(\xi_{\text {opt }}\right)$

$$
\xi_{\mathrm{opt}}=\frac{1}{\sqrt{\lambda}} .
$$

Equation (13) reveals that the thicknesses of the bilayers $t_{1}$ and $t_{2}$ should be such that the forces associated with their respective moments $M_{1}$ and $M_{2}$ across any section should be equal in order to achieve the optimal slope for a given pair of materials; i.e., $\left(M_{1} / t_{1}\right)=\left(M_{2} / t_{2}\right)$. Therefore, solving (9), (10), and (13) gives the optimal normalized free-end slope

$$
\left(\Theta_{\mathrm{n}}\right)_{\mathrm{opt}}=\frac{\left(\Theta_{\mathrm{th}}\right)_{\mathrm{opt}}}{6(\Delta \mathrm{T}) \beta}=\frac{(\Delta \alpha)}{4} .
$$

From (14), it is clear that the optimal normalized slope for a thermally actuated bimaterial is dependent only on the difference in thermal expansion coefficients, $\Delta \alpha$ of the two materials. However, the optimal thickness ratio does depend on the modulus ratio; $\lambda$. Fig. 3 shows a plot of optimal thickness ratio $\xi_{\text {opt }}$ as a function of $\lambda$. It is clear from the plot that decreasing $\lambda$ must be compensated by an increase in $\xi_{\text {opt }}$ for an optimal performance corresponding to a particular material combination. 
TABLE II

Optimal Normalized Work Per Volume, $(\mathrm{Wn})_{\mathrm{opt}}$ FOR Different Thin Films on VARIOUS Substrates Considered. All Units aRe in PaK ${ }^{-2}$

\begin{tabular}{|c|c|c|c|c|c|}
\hline & $\mathrm{Ni}$ & $\mathrm{Cu}$ & $\mathrm{Al}$ & $\mathrm{Au}$ & Polyimide \\
\hline $\mathrm{SiO}_{2}$ & 0.42 & 0.52 & 0.90 & 0.32 & 0.09 \\
\hline $\mathrm{Si}_{3} \mathrm{~N}_{4}$ & 0.57 & 0.70 & 1.25 & 0.38 & 0.09 \\
\hline $\mathrm{DLC}$ & 1.16 & 1.23 & 1.93 & 0.67 & 0.11 \\
\hline $\mathrm{SiC}$ & 0.51 & 0.66 & 1.26 & 0.33 & 0.08 \\
\hline $\mathrm{Si}$ & 0.49 & 0.60 & 1.09 & 0.34 & 0.08 \\
\hline
\end{tabular}

\section{B. Optimization of Blocked Moment $\left(\mathrm{M}_{\mathrm{blk}}\right)$}

From (6) it is evident that the blocked moment developed by a thermal bimaterial actuator depends on the properties of the bimaterial employed and the thickness ratio for a constant thickness $(\mathrm{t})$ under a given temperature change $(\Delta \mathrm{T})$. Using (6) a nondimensional parameter $\left(\mathrm{M}_{\mathrm{I}}\right)$, the moment index is defined as follows:

$$
\mathrm{M}_{\mathrm{I}}=\frac{\mathrm{M}_{\mathrm{n}}}{\mathrm{E}_{1}(\Delta \alpha)}=\frac{1}{2 \mathrm{Z}_{\mathrm{M}}}
$$

where $\mathrm{M}_{\mathrm{n}}=\left(\mathrm{M}_{\mathrm{blk}} / \mathrm{t}^{2}(\Delta \mathrm{T})\right)$, the blocked moment normalized by $\mathrm{t}^{2}(\Delta \mathrm{T})$

$$
\text { Where } \quad \mathrm{Z}_{\mathrm{M}}=\frac{(\xi+1)}{\xi}(\lambda \xi+1)
$$

The moment index $M_{I}$ should be maximized in order to achieve maximum $M_{n}\left(M_{b l k}\right)$. Hence, $Z_{M}$ should be minimized subject to

$$
\lambda>0 \text { is constant and } \xi>0 .
$$

The optimal thickness ratio for a given pair of materials that minimizes $\mathrm{Z}_{\mathrm{M}}$ is obtained by

$$
\frac{\partial \mathrm{Z}_{\mathrm{M}}}{\partial \xi}=0 \text { for a constant } \lambda .
$$

Substituting (16) in (18) gives one admissible solution for the optimal thickness ratio $\xi_{\text {opt }}$ that minimizes $\mathrm{Z}_{\mathrm{M}}$ and this is same as that given by (13). This is because the $\mathrm{M}_{\mathrm{blk}}$ developed is directly proportional to $\Theta_{\text {th }}$ and, hence, the optimality condition pertaining to $\Theta_{\text {th }}$ also corresponds to that of $\mathrm{M}_{\mathrm{blk}}$ and, hence, Fig. 3 can also be utilized.

Solving (13), (15), and (16) give the optimal normalized blocked moment for a given pair of materials.

$$
\left(\mathrm{M}_{\mathrm{n}}\right)_{\mathrm{opt}}=\frac{\mathrm{E}_{1}(\Delta \alpha)}{2\left(\frac{\xi_{\mathrm{opt}}+1}{\xi_{\mathrm{opt}}}\right)^{2}} .
$$

Fig. 4 shows the contours for $\left(\mathrm{M}_{\mathrm{n}}\right)_{\mathrm{opt}}$ developed by a bimaterial actuator as a function of $\mathrm{E}_{1}(\Delta \alpha)$ and $\xi_{\text {opt }}$. It is clear from the graph that if one of the materials in a bimaterial is replaced by another material with a lower Young's modulus and larger thermal expansion coefficient, then its thickness has to be increased in accordance to the (13) to obtain a maximum blocked moment corresponding to that particular material pair.

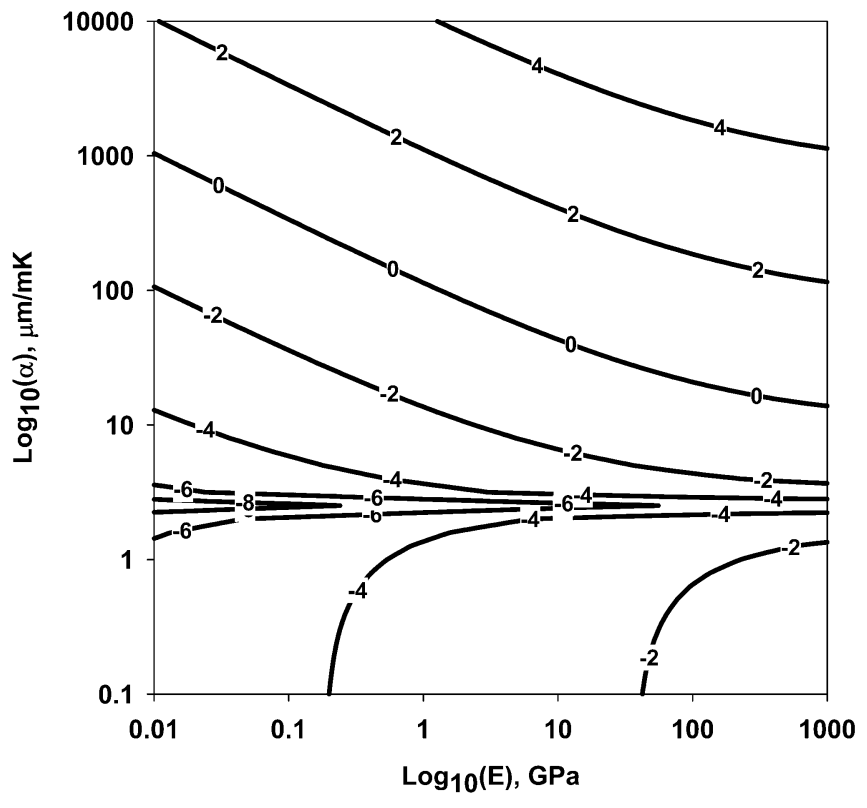

Fig. 8. Contours of $\log _{10}\left(W_{n}\right)_{\text {opt }}$ for different materials on a silicon substrate.

\section{Optimization of Maximum Work per Volume (W)}

As illustrated by (7) the maximum work per volume (W) for an actuator is directly proportional to the product of the blocked moment $M_{b l k}$ and free-end slope $\Theta_{t h}$. Since the optimality condition for the free-end slope and blocked moment corresponds to the relation given by (13), the optimality condition for $\mathrm{W}$ also converges to the same relation. Using (8), a nondimensional parameter $\left(E_{\mathrm{I}}\right)$, the energy index can be defined

$$
\mathrm{E}_{\mathrm{I}}=\frac{\mathrm{W}_{\mathrm{n}}}{\mathrm{E}_{1}(\Delta \alpha)^{2}}=\frac{3}{8 \mathrm{Z}_{\mathrm{E}}}
$$

where $\mathrm{W}_{\mathrm{n}}=\mathrm{W} /(\Delta \mathrm{T})^{2}$, the maximum work per volume normalized by $(\Delta \mathrm{T})^{2}$

$$
\mathrm{Z}_{\mathrm{E}}=\frac{(1+\lambda \xi)^{2}\left(1+\xi^{3} \lambda\right)}{\lambda \xi^{2}(\xi+1)}+\frac{3(\lambda \xi+1)(\xi+1)}{\xi} .
$$

The optimal normalized work for a given pair of materials is obtained by solving (13), (20), and (21).

$$
\left(\mathrm{W}_{\mathrm{n}}\right)_{\mathrm{opt}}=\frac{3 \mathrm{E}_{1}(\Delta \alpha)^{2}}{32\left(\frac{\xi_{\mathrm{opt}}+1}{\xi_{\mathrm{opt}}}\right)^{2}} .
$$

Fig. 5 shows a plot of $\left(\mathrm{W}_{\mathrm{n}}\right)_{\mathrm{opt}}$ for a given pair of materials as a function of $\mathrm{E}_{1}(\Delta \alpha)^{2}$ and $\xi_{\text {opt }}$ based on (22). 


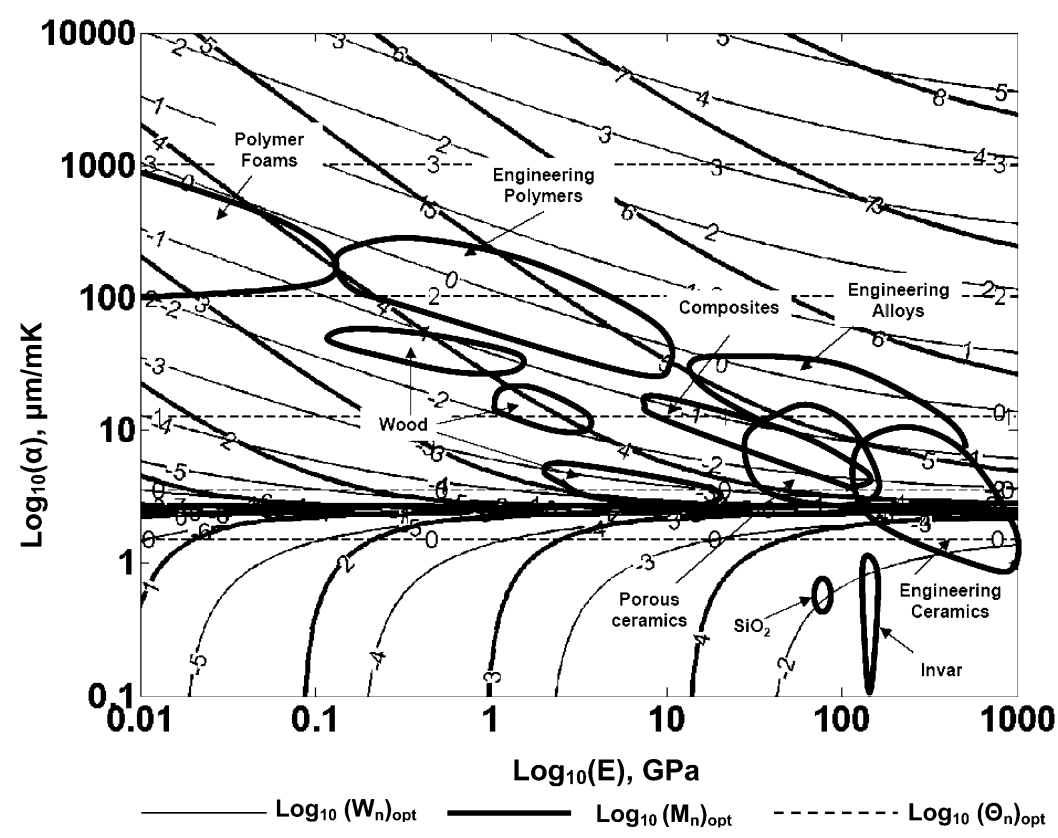

Fig. 9. Contours of equal performance for different classes of materials on a silicon substrate plotted on Ashby's selection chart [20].

\section{CANDidATE MATERIALS FOR Bimaterial ACTUATOR DESIGN}

Before exploring the optimal choice of materials and their corresponding thickness ratio it is worthwhile to understand the tradeoffs between force and displacement for a restricted combination of materials. Table I list the properties of a limited range of materials, which have been previously considered for MEMS actuators.

Fig. 6 shows a comparison of the operating characteristics (normalized moment versus normalized slope) of thermal bimaterial actuators made of metals and polymer $(\mathrm{Ni}, \mathrm{Cu}, \mathrm{Al}, \mathrm{Au}$, and polyimide) on various substrates $\left(\mathrm{SiO}_{\mathrm{X}}, \mathrm{SiN}_{\mathrm{X}}, \mathrm{DLC}, \mathrm{SiC}\right.$ and $\mathrm{Si}$ ) for a particular thickness ratio $(\xi=0.5)$. It is apparent that there are significant differences in performance among the limited choices considered. Graphs of the form shown in Fig. 6, which correspond to (9) and (15), are useful in selecting an optimal material pair for a fixed value of thickness ratio, $\xi$ within the range of choices considered.

Fig. 7 shows comparison of the energy index $\left(\mathrm{E}_{\mathrm{I}}\right)$ at different thickness ratios $(\xi)$ for the same range of thin films on substrates. This set of curves, corresponding to (20) illustrates that there is an optimum thickness ratio for a given pair of materials at which maximum work can be delivered. The graphs shown in Fig. 7 are useful in identifying the best thickness ratio for a given pair of materials. Table II shows the maximum normalized work that can be achieved for different thin films on the various substrates considered.

In order to make a more effective selection spanning the material domain it is useful to take a different strategy. Ashby [20] has shown the utility of employing selection maps by classifying the material kingdom into specific classes within the domain of various material properties. These selection maps can be modified for the current purpose of materials selection for thermal bimaterial actuators. By fixing one material, it is possible to plot contours of iso-performance on the selection map for a wide range of available materials. New materials for thermal bimaterial actuators can be explored by plotting contours of $\left(\mathrm{W}_{\mathrm{n}}\right)_{\mathrm{opt}}$ in the domain of governing properties (Young's modulus, E and thermal expansion co-efficient, $\alpha$ ). Fig. 8 shows contours of optimal normalized work plotted with respect to a silicon substrate. New candidate materials for any substrate can be identified by comparing the performance contours corresponding to it with other candidate materials.

Fig. 9 shows contours for optimal performance with reference to silicon overlaid on Ashby's selection map in the domain of $\mathrm{E}-\alpha$. The contour lines corresponding to $\left(\mathrm{M}_{\mathrm{n}}\right)_{\mathrm{opt}}$ are linear and parallel to constant $\mathrm{E} \alpha$ lines in the Ashby's chart while the contours of $\left(\mathrm{W}_{\mathrm{n}}\right)_{\mathrm{opt}}$ are parabolic. Both these contours become asymptotic at the properties of silicon. Contours of $\left(\Theta_{n}\right)_{\text {opt }}$ are straight lines parallel to the abscissa because it is independent of Young's modulus of the materials as shown in (14). It is clear from this plot that engineering polymers and engineering alloys promise the highest $\left(\mathrm{W}_{\mathrm{n}}\right)_{\mathrm{opt}}$ on silicon substrates within the range considered. Critical examination of materials in these classes reveals polymers [polymethylmethacrylate (PMMA), polystyrene (PS), nylon, melamine (MEL), polydimethylsiloxane (PDMS)], and metals (beryllium, steel, zinc, copper), which have not been widely considered for thermal bimaterial actuators. It should be noted that the polymers require a very large thickness on silicon substrates to compensate for their low Young's modulus, which may be inadmissible in some applications.

Optimization based on normalized work is useful for identifying materials capable of delivering both large moment and slope. Table III shows a comparison of the performance of a few engineering polymers and alloys that deliver $\left(\mathrm{W}_{\mathrm{n}}\right)_{\mathrm{opt}}$ significantly greater than $\sim 0.1 \mathrm{PaK}^{-2}$ (i.e., $\log _{10}\left(\mathrm{~W}_{\mathrm{n}}\right)_{\mathrm{opt}}>-1$ ) on three different substrates $\left(\mathrm{Si}, \mathrm{SiO}_{2}\right.$ and PMMA). As expected, polymers deliver large slope and small moment while metals deliver vice versa. For applications such as micropumps, 
TABLE III

CANDidate Materials for Thermal Bimaterial Actuators Which CAn Deliver Large (Wn) opt On Different SubStRates

\begin{tabular}{|c|c|c|c|c|c|c|c|c|c|c|c|c|c|c|c|}
\hline \multirow[b]{3}{*}{ S.No } & \multirow{3}{*}{$\begin{array}{l}\text { Candidate } \\
\text { Materials }\end{array}$} & \multirow[b]{2}{*}{$\mathbf{E}_{2}$} & \multirow[b]{2}{*}{$a_{2}$} & \multicolumn{4}{|c|}{$\mathrm{Si}\left[\mathrm{E}_{1}=165 \mathrm{GPA}, \alpha_{1}=2.49 \mu \mathrm{m} / \mathrm{mK}\right]$} & \multicolumn{4}{|c|}{$\mathrm{SiO}_{2}\left[\mathrm{E}_{1}=75 \mathrm{GPA}, \alpha_{1}=0.4 \mu \mathrm{m} / \mathrm{mK}\right]$} & \multicolumn{4}{|c|}{ PMMA [ $E_{1}=2.5$ GPA, $\left.\alpha_{1}=75 \mu \mathrm{m} / \mathrm{mK}\right]$} \\
\hline & & & & $(\mathbf{W n})_{\mathrm{opt}}$ & $\mathbf{M}_{\mathrm{n}}$ & $\Theta_{\mathrm{n}}$ & $\eta_{\mathrm{s}}$ & $(\mathbf{W n})_{\mathrm{opt}}$ & $\mathbf{M}_{\mathrm{n}}$ & $\Theta_{\mathrm{n}}$ & $\eta_{s}$ & $(\mathbf{W n})_{\mathrm{opt}}$ & $\overline{\mathbf{M}_{\mathbf{n}}}$ & $\Theta_{\mathrm{n}}$ & $\overline{\eta_{s}}$ \\
\hline & & GPA & $\mu \mathrm{m} / \mathrm{mK}$ & $\mathrm{PaK}^{-2}$ & MPaK $^{-1}$ & $\mathbf{X 1 0 ^ { 6 } \mathrm { K } ^ { - 1 }}$ & & $\mathbf{P a K}^{-2}$ & MPaK $^{-1}$ & $\mathbf{X 1 0 ^ { 6 } \mathrm { K } ^ { - 1 }}$ & & $\mathrm{PaK}^{-2}$ & MPaK $^{-1}$ & $\times 10^{6} \mathrm{~K}^{-1}$ & \\
\hline 1 & $\mathrm{Be}$ & 303.00 & 11.50 & 0.42 & 0.25 & 13.52 & 0.02 & 0.39 & 0.19 & 16.65 & 0.02 & 0.79 & 0.07 & 95.25 & 0.03 \\
\hline 2 & Steel & 207.00 & 13.10 & 0.49 & 0.24 & 15.92 & 0.03 & 0.44 & 0.19 & 19.05 & 0.02 & 0.73 & 0.06 & 92.85 & 0.03 \\
\hline 3 & $\overline{Z n}$ & 97.00 & 31.20 & 2.40 & 0.45 & 43.07 & 0.05 & 1.89 & 0.33 & 46.20 & 0.04 & 0.33 & 0.04 & 65.70 & 0.01 \\
\hline 4 & $\mathrm{Cu}$ & 110.00 & 16.40 & 0.60 & 0.23 & 20.87 & 0.04 & 0.54 & 0.18 & 24.00 & 0.04 & 0.61 & 0.06 & 87.90 & 0.03 \\
\hline 5 & $\mathrm{Mg}$ & 45.00 & 26.10 & 1.01 & 0.23 & 35.42 & 0.06 & 0.88 & 0.18 & 38.55 & 0.06 & 0.37 & 0.04 & 73.35 & 0.02 \\
\hline 6 & PMMA & 2.50 & 75.00 & 0.98 & 0.07 & 108.77 & 0.13 & 0.93 & 0.07 & 111.90 & 0.13 & - & - & - & - \\
\hline 7 & PS & 3.00 & 72.50 & 1.07 & 0.08 & 105.02 & 0.13 & 1.02 & 0.08 & 108.15 & 0.13 & - & - & - & - \\
\hline 8 & Nylon & 0.62 & 80.00 & 0.31 & 0.02 & 116.27 & 0.12 & 0.31 & 0.02 & 119.40 & 0.16 & - & - & - & - \\
\hline 9 & $\overline{M E L}$ & 8.00 & 40.00 & 0.71 & 0.10 & 56.27 & 0.10 & 0.67 & 0.09 & 59.40 & 0.10 & 0.12 & 0.02 & 52.50 & 0.01 \\
\hline 10 & PDMS & 4.00 & 60.00 & 0.93 & 0.09 & 86.27 & 0.12 & 0.88 & 0.08 & 89.40 & 0.12 & $\overline{-}$ & - & - & - \\
\hline 12 & Epoxies & 2.00 & 55.00 & 0.42 & 0.04 & 78.77 & 0.12 & 0.41 & 0.04 & 81.90 & 0.14 & - & - & - & - \\
\hline 13 & $\overline{\mathrm{PP}}$ & 2.00 & 120.00 & 2.10 & 0.10 & 176.27 & 0.14 & 1.98 & 0.09 & 179.40 & 0.14 & 0.11 & 0.01 & 67.50 & 0.00 \\
\hline 14 & $\mathrm{~Pb}$ & 14.00 & 29.10 & 0.56 & 0.11 & 39.92 & 0.09 & 0.53 & 0.10 & 43.05 & 0.09 & 0.24 & 0.03 & 68.85 & 0.02 \\
\hline 15 & $\mathrm{Ni}$ & 207.00 & 13.10 & 0.49 & 0.24 & 15.92 & 0.03 & 0.44 & 0.19 & 19.05 & 0.02 & 0.73 & 0.06 & 92.85 & 0.03 \\
\hline 16 & $\overline{\mathrm{Ti}}$ & 110.00 & 9.00 & 0.13 & 0.11 & 9.77 & 0.03 & 0.16 & 0.10 & 12.90 & 0.03 & 0.77 & 0.06 & 99.00 & 0.07 \\
\hline 17 & $\mathrm{BeO}$ & 345.00 & 7.00 & 0.11 & 0.13 & 6.77 & 0.01 & 0.14 & 0.12 & 9.90 & 0.02 & 0.92 & 0.07 & 102.00 & 0.06 \\
\hline 18 & $\mathrm{Al}_{2} \mathrm{O}_{3}$ & 370.00 & 7.40 & 0.13 & 0.15 & 7.37 & 0.01 & 0.16 & 0.12 & 10.50 & 0.02 & 0.91 & 0.07 & 101.40 & 0.05 \\
\hline 19 & Cast Iron & 165.00 & 12.00 & 0.35 & 0.20 & 14.27 & 0.03 & 0.34 & 0.16 & 17.40 & 0.03 & 0.74 & 0.06 & 94.50 & 0.04 \\
\hline 20 & $\mathrm{Al}$ & 68.00 & 24.00 & 1.09 & 0.27 & 32.27 & 0.05 & 0.93 & 0.21 & 35.40 & 0.05 & 0.43 & 0.04 & 76.50 & 0.02 \\
\hline 21 & $\mathrm{Zr}_{2} \mathrm{O}_{3}$ & 200.00 & 12.00 & 0.38 & 0.22 & 14.27 & 0.03 & 0.36 & 0.17 & 17.40 & 0.03 & 0.75 & 0.06 & 94.50 & 0.04 \\
\hline 22 & $\mathrm{~W}$ & 400.00 & 4.30 & - & - & - & - & - & - & - & - & 1.01 & 0.08 & 106.05 & 0.09 \\
\hline 23 & B & 320.00 & 8.30 & 0.18 & 0.16 & 8.72 & 0.02 & 0.20 & 0.13 & 11.85 & 0.02 & 0.88 & 0.07 & 100.05 & 0.05 \\
\hline 24 & $\mathrm{Nb}$ & 105.00 & 7.30 & - & - & - & - & 0.10 & 0.08 & 10.35 & 0.04 & 0.81 & 0.06 & 101.55 & 0.08 \\
\hline 25 & $\mathrm{Ge}$ & 102.00 & 5.75 & - & - & - & - & - & - & - & - & 0.84 & 0.06 & 103.88 & 0.10 \\
\hline 26 & $\mathrm{Si}$ & 165.00 & 2.49 & - & - & - & - & - & - & - & - & 0.93 & 0.07 & 108.77 & 0.12 \\
\hline 27 & $\mathrm{SiO}_{2}$ & 75.00 & 0.40 & - & - & - & - & - & - & - & - & 0.93 & 0.07 & 111.90 & 0.13 \\
\hline 28 & $\mathrm{Si}_{3} \mathrm{~N}_{4}$ & 300.00 & 2.80 & - & - & - & - & - & - & - & - & 1.03 & 0.08 & 108.30 & 0.12 \\
\hline 29 & DLC & 700.00 & 1.18 & - & - & - & - & - & - & - & - & 1.14 & 0.08 & 110.73 & 0.15 \\
\hline 30 & Invar & 145.00 & 0.36 & - & - & - & - & - & - & - & - & 1.02 & 0.07 & 111.96 & 0.14 \\
\hline
\end{tabular}

where work/volume is the relevant metric it is desirable to use materials capable of delivering a reasonably large moment and slope. Materials such as Epoxies, $\mathrm{Zn}, \mathrm{Al}, \mathrm{Mg}$, PDMS, MEL, $\mathrm{Pb}, \mathrm{Cu}$, Steel, and $\mathrm{Ni}$ on $\mathrm{Si} / \mathrm{SiO}_{2}$ substrates and $\mathrm{Ti}, \mathrm{Zn}$ on a PMMA substrate deliver a reasonably large $\left(\mathrm{W}_{\mathrm{n}}\right)_{\mathrm{opt}}$ with corresponding $\mathrm{M}_{\mathrm{n}}$ varying between $0.04-0.4 \mathrm{MPaK}^{-1}$ and $\Theta_{\mathrm{n}}$ between $20 \times 10^{-6}-90 \times 10^{-6} \mathrm{~K}^{-1}$. Some of these combinations have not been considered so far for thermal bimaterial actuators for applications requiring a large work per volume. Fig. 10(a) and 10(b) shows contours of optimal normalized work plotted with reference to $\mathrm{SiO}_{2}$ and PMMA substrates, respectively.

A similar analysis is carried out to identify the materials that can be considered for large moment applications. Table IV lists a selection of materials identified from such plots for optimal normalized moment significantly greater than $\sim 0.1 \mathrm{MPaK}^{-1}$ 


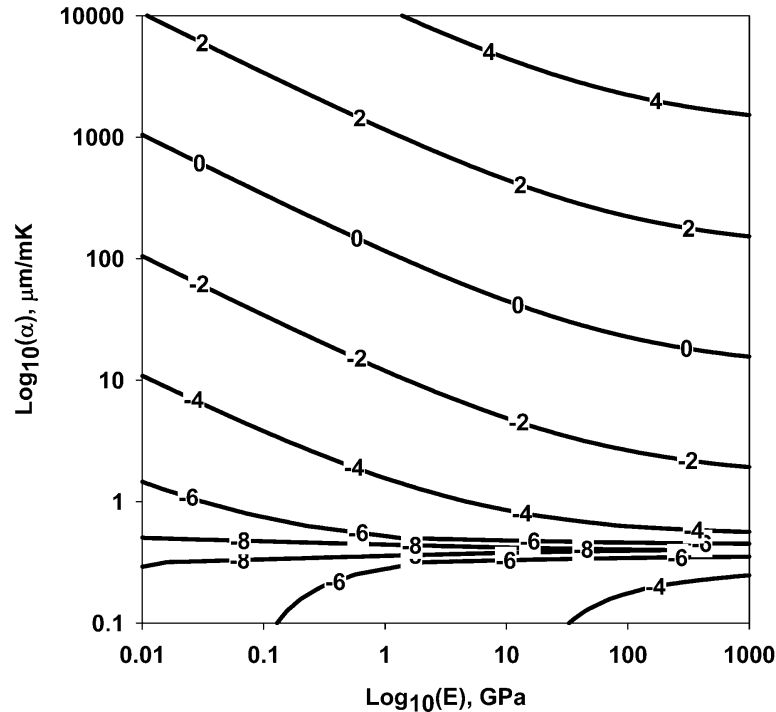

(a)

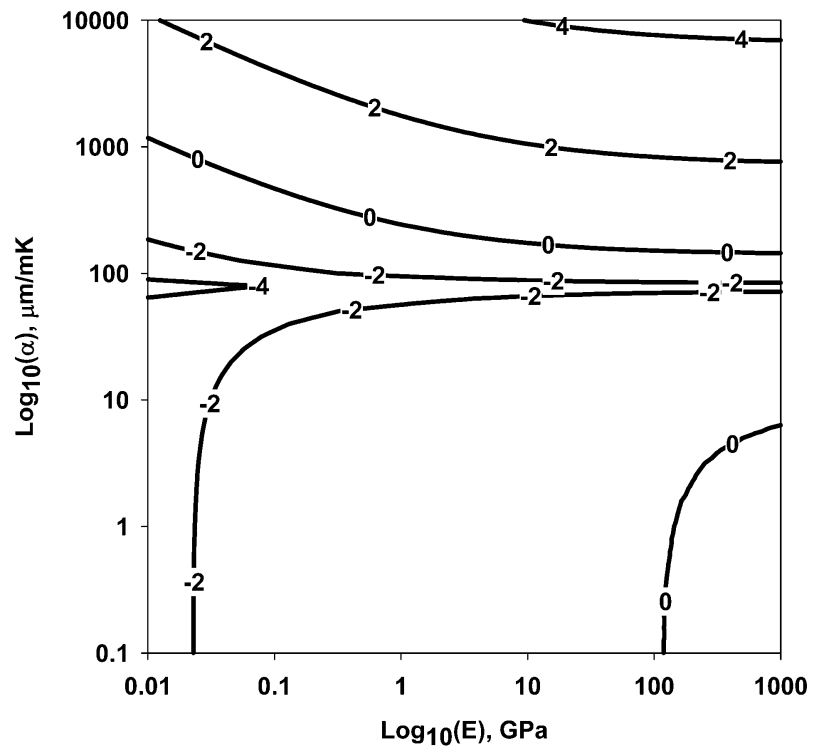

(b)

Fig. 10. Contours of $\log _{10}\left(\mathrm{~W}_{\mathrm{n}}\right)_{\mathrm{opt}}$ with reference to: (a) $\mathrm{SiO}_{2}$ substrate: (b) PMMA substrate.

for the same three different substrates. It is clear for this result that few engineering alloys and ceramics, including $\mathrm{Zn}$, $\mathrm{Al}, \mathrm{Mg}$, Steel, $\mathrm{Ni}, \mathrm{Be}, \mathrm{Cu}$, and $\mathrm{Zr}_{2} \mathrm{O}_{3}$ on $\mathrm{Si}$ or $\mathrm{SiO}_{2}$ deliver a large moment while polymers deliver a relatively small force. Fig. 11(a) and 11(b) shows contours of optimal normalized moment with reference to $\mathrm{SiO}_{2}$ and PMMA, respectively.

For applications where a large slope is the relevant metric, materials such as PP, Nylon, PMMA, PDMS, Epoxies, and PS on $\mathrm{Si}$ or $\mathrm{SiO}_{2}, \mathrm{Ge}, \mathrm{BeO}, \mathrm{Nb}$, Invar, and ceramic substrates deliver $\left(\Theta_{\mathrm{n}}\right)_{\mathrm{opt}}$ of order $10^{-4} \mathrm{~K}^{-1}$. Therefore, it is apparent from Fig. 9 that polymers can be considered favorably for such applications although the nonlinear time and temperature dependent response of polymers require further consideration.

Another factor to be considered in materials selection based on work per volume is the structural efficiency of the actuator $\left(\eta_{\mathrm{s}}\right)$, which is defined here as the ratio of maximum work per volume, $\mathrm{W}$ of a thermally actuated bimaterial to the total strain energy per volume of the two individual material layers that constitutes the bimaterial. From Table III, it is clear that, although polymers deliver a much lower moment, they offer higher efficiency on the various substrates considered compared to metals.

\section{DISCUSSION}

The choice of a particular material for an actuator design also depends on its compatibility with the fabrication process, the ability to achieve the desired shape and the functionality required [20]. The methodology for materials selection for thermal bimaterial actuators described earlier is based on the mechanics of actuation. This reveals a few candidate materials from the large set of materials available. However, the success of an actuator design depends on the extent to which the defined performance metrics capture the overall required performance. Therefore, the suitability of these candidate materials for a thermal bimaterial actuator has to be further explored by considering additional factors such as the maximum actuation temperature, power requirements, dissipation effects due to heat loss, compatibility with micromachining and, of course, the cost. Further research is still underway considering some of these additional factors, which could further refine the materials selection process. The key aim of this paper is to obtain a ranking of different material combinations during preliminary design. Therefore, the present materials selection strategy has not accounted for the variation in material properties due to temperature and scale, and assumes a linear elastic material model for all classes of materials over the entire temperature range. Clearly this is an error, particularly for polymers. Nevertheless, the present approach has utility in selecting candidate materials for thermal bimaterial actuators.

In the preliminary design phase, the candidate materials are selected based on the primary performance requirements as described by the performance metrics defined herein. These candidate materials need to be further filtered based on other considerations such as maximum actuation temperature which is also limited by the yield/fracture strength of the materials at the microscale, power requirements which are determined by the electrical property (i.e., resistivity) of the materials, heat dissipation which is dictated by the thermal properties (thermal conductivity and emissivity) and flow physics (convective effects) and the residual stresses developed during micromachining processes. Besides these design constraints, application specific requirements such as response time, sensitivity and linearity will also have a bearing on the selection of the materials. However, for many applications, there is likely to be a finite, small temperature limit, $\sim 100{ }^{\circ} \mathrm{C}$, which is well within the capabilities of almost all the materials explored. For such applications the process described herein is directly applicable.

Perhaps the most significant result of this paper is the confirmation that existing microfabricatable materials (such as aluminium and silicon) offer good options for high performance thermal bimaterial actuators. The order of $\left(\mathrm{W}_{\mathrm{n}}\right)_{\mathrm{opt}}$ for DLC on metallic substrates such as $\mathrm{Ni}, \mathrm{Cu}$, and $\mathrm{Al}$ is same as $\mathrm{Al}$ on $\mathrm{Si}$. Therefore, for high work or force actuators, $\mathrm{Al}$ on $\mathrm{Si}\left(\left(\mathrm{W}_{\mathrm{n}}\right)_{\mathrm{opt}}=1.09 \mathrm{PaK}^{-2},\left(\mathrm{M}_{\mathrm{n}}\right)_{\mathrm{opt}}=0.23 \mathrm{MPaK}^{-1}\right)$, is a 
TABLE IV

CANDidate Materials for Thermal Bimaterial Actuators Which CAN Deliver Large $\left(\mathrm{M}_{\mathrm{n}}\right)_{\text {opt }}$ ON DifFerent SubStrates

\begin{tabular}{|c|c|c|c|c|c|c|}
\hline \multirow{2}{*}{ S.No } & \multirow{2}{*}{$\begin{array}{l}\text { Candidate } \\
\text { materials }\end{array}$} & $\mathbf{E}_{2}$ & $\alpha_{2}$ & $\mathrm{Si}\left[\mathrm{E}_{1}, \alpha_{1}\right]$ & $\mathrm{SiO}_{2}\left[\mathrm{E}_{1}, \mathrm{a}_{1}\right]$ & PMMA $\left[\mathrm{E}_{1}, \boldsymbol{\alpha}_{1}\right]$ \\
\hline & & GPA & $\mu \mathrm{m} / \mathrm{mK}$ & MPaK $^{-1}$ & MPaK $^{-1}$ & MPaK $^{-1}$ \\
\hline 1 & $\mathrm{Be}$ & 303 & 11.5 & 0.20 & 0.19 & 0.07 \\
\hline 2 & Steel & 207 & 13.1 & 0.20 & 0.19 & 0.06 \\
\hline 3 & $\mathrm{Zn}$ & 97 & 31.2 & 0.37 & 0.33 & 0.04 \\
\hline 4 & $\mathrm{Cu}$ & 110 & 16.4 & 0.19 & 0.18 & 0.06 \\
\hline 5 & $\mathrm{Mg}$ & 45 & 26.1 & 0.20 & 0.18 & 0.04 \\
\hline 6 & PMMA & 2.5 & 75 & 0.07 & 0.07 & - \\
\hline 7 & PS & 3 & 72.5 & 0.08 & 0.08 & - \\
\hline 8 & Nylon & 0.62 & 80 & - & - & - \\
\hline 9 & MEL & 8 & 40 & 0.09 & 0.09 & - \\
\hline 10 & PDMS & 4 & 60 & 0.08 & 0.08 & - \\
\hline 12 & Epoxies & 2 & 55 & - & - & - \\
\hline 13 & PP & 2 & 120 & 0.09 & 0.09 & - \\
\hline 14 & $\mathrm{~Pb}$ & 14 & 29.1 & 0.10 & 0.10 & - \\
\hline 15 & $\mathrm{Ni}$ & 207 & 13.1 & 0.20 & 0.19 & 0.06 \\
\hline 16 & $\mathrm{Ti}$ & 110 & 9 & 0.09 & 0.10 & 0.06 \\
\hline 17 & $\mathrm{BeO}$ & 345 & 7 & 0.10 & 0.12 & 0.07 \\
\hline 18 & $\mathrm{Al}_{2} \mathrm{O}_{3}$ & 370 & 7.4 & 0.11 & 0.12 & 0.07 \\
\hline 19 & Cast Iron & 165 & 12 & 0.16 & 0.16 & 0.06 \\
\hline 20 & $\mathrm{Al}$ & 68 & 24 & 0.23 & 0.21 & - \\
\hline 21 & $\mathrm{Zr}_{2} \mathrm{O}_{3}$ & 200 & 12 & 0.17 & 0.17 & 0.06 \\
\hline 22 & W & 400 & 4.3 & 0.04 & 0.07 & 0.08 \\
\hline 23 & B & 320 & 8.3 & 0.13 & 0.13 & 0.07 \\
\hline 24 & $\mathrm{Nb}$ & 105 & 7.3 & 0.07 & 0.08 & 0.06 \\
\hline 25 & $\mathrm{Ge}$ & 102 & 5.75 & - & 0.06 & 0.06 \\
\hline 26 & $\mathrm{Si}$ & 112 & 2.49 & - & - & 0.07 \\
\hline 27 & $\mathrm{SiO}_{2}$ & 75 & 0.4 & - & - & 0.07 \\
\hline 28 & $\mathrm{Si}_{3} \mathrm{~N}_{4}$ & 300 & 2.8 & - & - & 0.08 \\
\hline 29 & DLC & 700 & 1.18 & - & - & 0.08 \\
\hline 30 & Invar & 145 & 0.36 & - & - & 0.07 \\
\hline
\end{tabular}




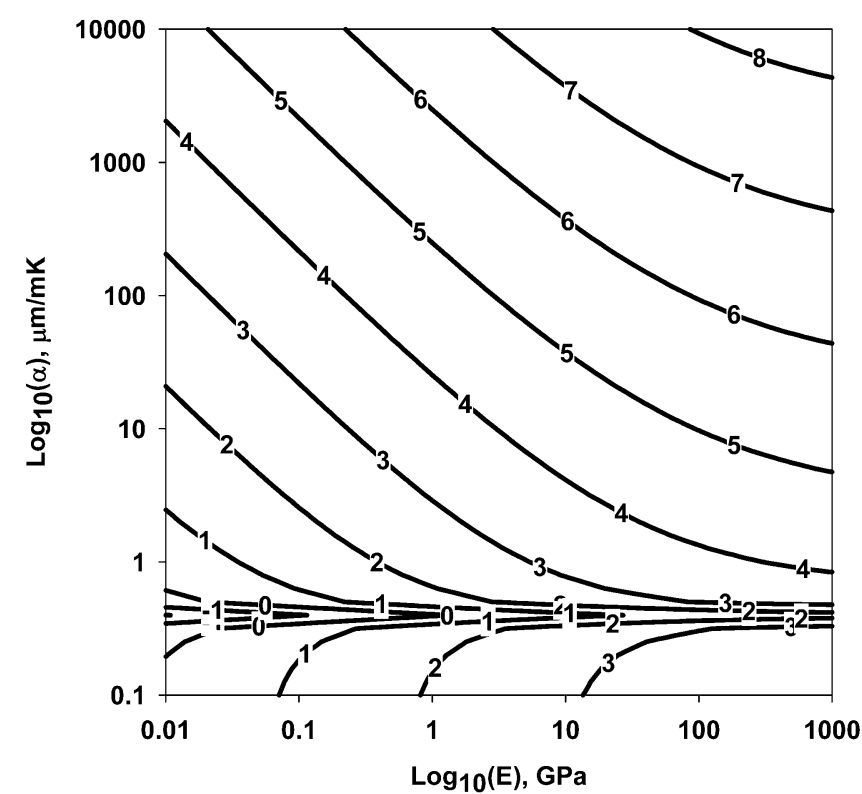

(a)

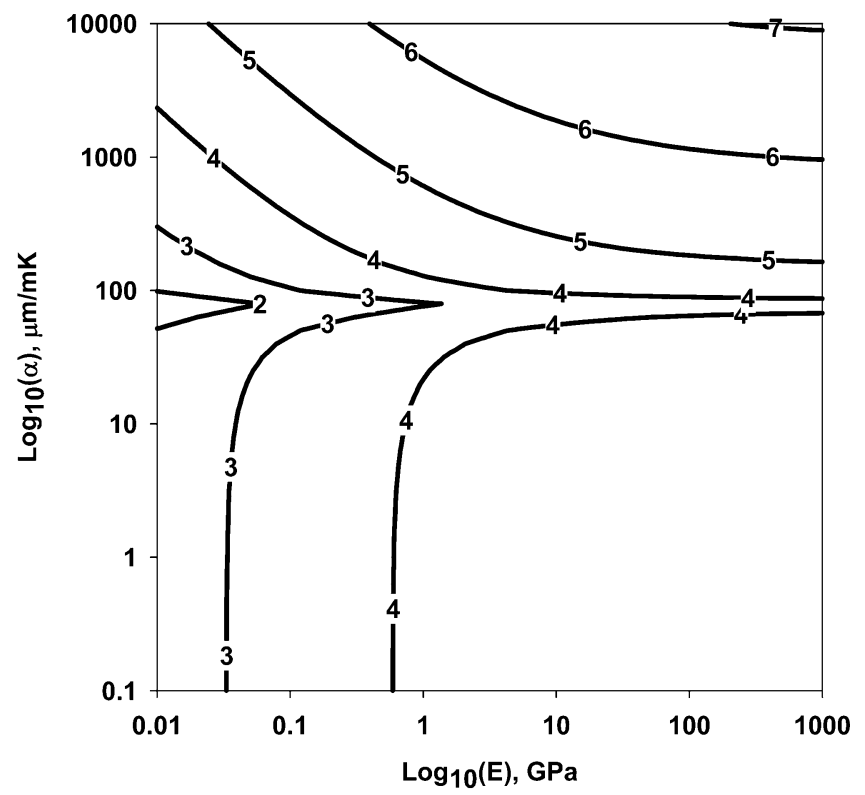

(b)

Fig. 11. Contours of $\log _{10}\left(M_{n}\right)_{\text {opt }}$ with reference to: (a) $\mathrm{SiO}_{2}$ substrate; (b) PMMA substrate.

very capable material combination that is significantly bettered only by $\mathrm{Zn}$ on $\mathrm{Si}\left(\left(\mathrm{W}_{\mathrm{n}}\right)_{\mathrm{opt}}=2.4 \mathrm{PaK}^{-2}\right.$, $\left.\left(\mathrm{M}_{\mathrm{n}}\right)_{\mathrm{opt}}=0.37 \mathrm{MPaK}^{-1}\right)$. For high displacement actuators, PMMA on $\mathrm{Si}\left(\Theta_{\mathrm{n}}=108.77 \times 10^{-6} \mathrm{~K}^{-1}\right)$ is comparable to any other choice. This observation also applies to possible alternate substrates, such as $\mathrm{SiO}_{2}$ or PMMA, which despite their extreme values of thermal expansion coefficient do not provide significant improvements over $\mathrm{Si}$ as the substrate material. A majority of materials belonging to different classes in the $\mathrm{E}-\alpha$ domain lies approximately between 0.1 to $1 \mathrm{PaK}^{-2}$. Hence, improvement in $\left(\mathrm{W}_{\mathrm{n}}\right)_{\text {opt }}$ beyond this order of magnitude is not achievable by optimal materials selection.

Zinc is one candidate that has not been used so far for microelectrothermal actuators despite its potentially superior per- formance to aluminium. $\mathrm{Zn} / \mathrm{ZnO}$ films of up to a few microns can be grown on silicon substrates by sputter deposition [21], [22]. Few published works are available characterizing zinc film properties relevant to microsystems applications. Therefore, the feasibility of using zinc for thermal bimaterial actuators would require a detailed investigation. By contrast, PMMA films of up to a few hundreds of microns can be coated on silicon by conventional spin coating, which is a proven fabrication route [23].

An important outcome of the present paper is the evolution of a strategy for the systematic selection of suitable candidate materials for bimaterial microelectrothermal actuators. This strategy can also be applied to select suitable candidate materials for other types of actuators such as piezoelectric, magnetostrictive and shape memory. The governing mechanics for these actuators is based on the relationship connecting the structural response, the field strength and the material parameters (piezoelectric strain coefficients for piezoelectric actuation and magnetostrictive coefficients for magnetostrictive actuation).

\section{CONCLUSION}

Closed form relations for performance metrics were derived using beam theory by applying structural mechanics relations. These performance metrics (free-end slope, blocked moment, and work per volume) that determine the operating characteristics of a bimaterial actuator were optimized for maximum performance for a given material pair and their corresponding optimal thickness ratios were evaluated. The suitability of conventional semiconductor materials for micromechanical transducer design was discussed relevant to performance enhancement and new candidate materials were obtained for silicon substrates by plotting iso-performance contours. Finally, an analytical framework for selecting novel material combinations for thermal bimaterial actuators was presented, which could serve as a useful tool for identifying potential candidate materials for future development.

\section{REFERENCES}

[1] S. M. Spearing, "Materials issues in microelectromechanical systems (MEMS)," Acta Materialia, vol. 48, pp. 179-196, 2000.

[2] D. J. Bell, T. J. Lu, N. A. Fleck, and S. M. Spearing, "MEMS actuators and sensors: Observation on their performance and selection for purpose," J. Micromech. Microeng., vol. 15, pp. S153-S164, 2005.

[3] J. K. Luo, J. H. He, Y. Q. Fu, A. J. Flewitt, S. M. Spearing, N. A. Fleck, and W. I. Milne, "Fabrication and characterization of diamondlike carbon/Ni bimorph normally closed microcages," J. Micromech. Microeng., vol. 15, pp. 1406-1413, 2005.

[4] N. T. Nguyen, S. S. Ho, and C. L. N. Low, "A polymeric micro gripper with integrated thermal actuators," J. Micromech. Microeng., vol. 14, pp. 969-974, 2004.

[5] M. Y. Al Aioubi, V. Djakov, S. E. Huq, and P. D. Prewett, "Deflection and load characterisation of bimorph actuators for bio MEMS and other applications," Microelectron. Eng., pp. 73-74, 2004, 898-903.

[6] J. S. Lee, D. S. Park, A. K. Nallani, G. S. Lee, and J. B. Lee, "Submicron metallic electrothermal actuators," J. Micromech. Microeng., vol. 15, pp. 322-327, 2005.

[7] J. Singh, T. Gan, A. Agarwal, M. Raj, and S. Liw, "3D free space thermally actuated micro mirror device," Sens. Actuators A, vol. 123-124, pp. 468-475, 2005.

[8] D. Bullen, X. Wang, J. Zou, S. W. Chung, C. A. Mirkin, and C. Liu, "Design, fabrication and characterization of thermally actuated probe arrays for dip pen nanolithography," J. Microelectromech. Syst., vol. 13 , no. 4, pp. 594-602, 2004. 
[9] A. J. Brook, S. J. Bending, J. Pinto, A. Oral, D. Ritchie, H. Beere, A. Springthorpe, and M. Henini, "Micromachined III-V cantilevers for AFM-tracking scanning Hall probe microscopy," J. Micromech. Microeng., vol. 13, pp. 124-128, 2003.

[10] M. Hopcroft, T. Kramer, G. Kim, K. Takashima, Y. Higo, D. Moore, and J. Brugger, "Micromechanical testing of SU-8 Cantilevers," in Int. Conf. Adv. Technol. Exp. Mech. JSME-MMD, 2003, pp. 1-6.

[11] R. R. A. Syms, H. Zou, J. Yao, D. Uttamchandani, and J. Stagg, "Scaleable electrothermal MEMS actuator for optical fibre alignment," J. Micromech. Microeng., vol. 14, pp. 1633-1639, 2004

[12] L. A. Field, D. L. Burriesci, P. R. Robrish, and R. C. Ruby, "Micromachined $1 \times 2$ optical fibre switch," Sens. Actuators A, vol. 53, pp. 311-315, 1996.

[13] P. Kopka, M. Hoffmann, and E. Voges, "Coupled U-shaped cantilever actuators for $1 \times 4$ and $2 \times 2$ optical fibre switch," J. Micromech. Microeng., vol. 10, pp. 260-264, 2000.

[14] M. Hoffmann, P. Kopka, and E. Voges, "Bistable micromechanical fibre optic switches on silicon with thermal actuators," Sens. Actuators $A$, vol. 78, pp. 28-35, 1999.

[15] X. X. Qu, Q. X. Zhang, Q. B. Zou, N. Balasubramanian, P. Yang, and K. Y.Zeng, "Characterization of Ti-Al alloy films for potential application in MEMS bimorph actuators," Mater. Sci. Semicond. Process., vol. 5, pp. 35-38, 2002.

[16] V. T. Srikar and S. M. Spearing, "Material selection in micromechanical design," J. Microelectromech. Syst., vol. 12, pp. 3-10, 2003.

[17] S. M. Spearing, "Design diagrams for layered materials," AIAA J., vol. 35, pp. 1638-1644, 1997.

[18] S. Timoshenko, "Analysis of bimetal thermostats," J. Opt. Soc. Amer., vol. 11, pp. 233-255, 1925.

[19] R. G. Budynas, Advanced Strength and Applied Stress Analysis, 2nd ed. New York: McGraw-Hill Int., 1999, pp. 302-309.

[20] M. F. Ashby, Material Selection in Mechanical Design, 1st ed. Oxford, U.K.: Pergamon, 1992, p. 45.

[21] G. Perluzzo, C. K. Jen, and E. L. Adler, "Characteristics of reactive magnetron sputtered $\mathrm{ZnO}$ films," in Proc. IEEE Ultrason. Symp., , 1989, pp. 373-376.

[22] Y. Zhu, H. Wang, and P. P. Ong, "Composite zinc/silicon nanocrystalline thin film: preparation, structures and the effect of oxidation on their photoluminescence," J. Phys.: Condensed Matter, vol. 13, pp. 787-795, 2001.
[23] L. Tan, Y. P. Kong, L. R. Bao, X. D. Huang, L. J. Guo, S. W. Pang, and A. F. Yee, "Imprinting polymer film on patterned substrates," J. Vac. Sci. Technol. B, vol. 21, no. 6, pp. 2742-2748, 2003.

Srinivasan Prasanna received the M.S. degree in mechanical engineering from the Indian Institute of Technology-Madras, Chennai, in 2000

$\mathrm{He}$ then worked as a design engineer for GE aircraft engines global engineering unit in Bangalore, India, from 2000 to 2003, where he was a member of the structural design team in development engine programs. He is currently a postgraduate research scholar in the materials research group within the School of Engineering Sciences at the University of Southampton, U.K. His research interests include design and analysis of structures at micro/nanoscales, materials and structures for the design of MEMS devices, mechanics of CNT structures, soild mechanics, heat transfer, and fluid flow analysis. He is currently involved in research that focuses on optimal materials selection for improving the performance of MEMS devices.

S. Mark Spearing received the Ph.D. degree from the Engineering Department at Cambridge University, U.K., in 1990.

In 2004, he was appointed Professor of Engineering Materials in the School of Engineering Sciences at The University of Southampton, U.K. Prior to this, he spent 10 years as Professor of Aeronautics and Astronautics at the Massachusetts Institute of Technology (MIT), Cambridge. His technical interests includes materials characterizations and structural analysis and design of MEMS, development of wafer-bonding technologies, microelectronic and MEMS packaging, and advanced composites. From 1995 to 2005, he was responsible for materials, structural design, and packaging tasks of the MIT MicroEngine, MicroRobot, Micro-Chemical Power, and MicroHydraulic Transducer projects as well as conducting cross-cutting underpinning technology development.

Dr. Spearing is an Associate Editor of the JOURNAL OF MicROELECTROMECHANICAL SYSTEMS and a Member of the American Society of Mechanical Engineers (ASME). In 2004, he received a Royal Society Wolfson Research Merit Award. 